\title{
Kinetic Modeling of Flocculation and Coalescence in the System Emulsion of Water-Xylene-Terbutyl Oleyl Glycosides
}

\author{
Harsa Pawignya ${ }^{1,2}$, Tutuk Djoko Kusworo ${ }^{1}$, Bambang Pramudono ${ }^{1^{*}}$ \\ ${ }^{1}$ Department of Chemical Engineering, Diponegoro University, Jl. Prof. Soedarto, Kampus Undip \\ Tembalang, Semarang 50239, Indonesia \\ ${ }_{2}^{2}$ Department of Chemical Engineering, Faculty of Industrial Engineering, University of Pembangunan \\ Nasional "Veteran" Yogyakarta, Yogyakarta 55283, Indonesia
}

Received: $2^{\text {nd }}$ May 2018; Revised: 17th September 2018; Accepted: 18 Available online: 25th January 2019; Published regularly: April 2019

\begin{abstract}
The development of a mathematical model for explaining the kinetics of flocculation and coalescence of emulsion droplets is essential to studying the stability of the kinetics emulsion system. Mathematic models were developed from the Van Den Tempel equation by modifying emulsion systems, and the emulsion was made by mixing water-xylene and surfactant tert-butyl oleyl glycosides (TBOG). Furthermore, this research studied the effect of stirrer speed on the value of flocculation rate constant $(a)$ and coalescence rate constant $(K)$. Moreover, the model identified the emulsion development condition controlled by either coalescence or flocculation. However, it was observed that under slow agitation $(1000 \mathrm{rpm})$ the emulsion development was controlled by flocculation mechanism, while a faster agitation (2000 rpm or higher) exhibited coalescence controlled mechanism. The results hereby confirmed that the $1^{\text {st }}$ model was the most appropriate for water-xylene-TBOG emulsion system. After analysing experimental data from four models, the $4^{\text {th }}$ model was discovered to be the most suitable, because it had the least error at $2.22 \%$. Copyright (C) 2019 BCREC Group. All rights reserved
\end{abstract}

Keywords: Kinetic; Emulsion; Flocculation; Coalescence

How to Cite: Pawignya, H., Kusworo, T.D., Pramudono, P. (2019). Kinetic Modeling of Flocculation and Coalescence in the System Emulsion of Water-Xylene-Terbutyl Oleyl Glycosides. Bulletin of Chemical Reaction Engineering \& Catalysis, 14 (1): 60-68 (doi:10.9767/bcrec.14.1.2594.60-68)

Permalink/DOI: https://doi.org/10.9767/bcrec.14.1.2594.60-68

\section{Introduction}

Emulsion systems are thermodynamically unstable and will generally be separated into two phases in a period of time. Emulsion instability can be determined by the occurrence of method-creaming or sedimentation, droplet flocculation, and coalescence among drops or phase segregation [1-3]. Emulsions mean two immis-

\footnotetext{
* Corresponding Author.

E-mail: bambangpraa@gmail.com (B. Pramudono)

Telp: +6224-7460058, Fax: +6224-74680675
}

cible liquids that are droplets of one phase (dispersed or internal phase) and dispersed in another (continuous phase or external phase) $[4,5]$. They can be applied to a variety of industries, such as: the cosmetics, chemicals, polishes, medicines, food, petroleum, and asphalt [6-8].

Kinetic model for the simultaneous processes of flocculation and coalescence in the emulsion system was investigated [9-11]. Some thermodynamics investigations have been known to modify the size, flocculation or coalescence of lipid 
molecules in the surrounding lipid emulsions [12].

This paper attempts to simultaneously measure both processes by developing a mathematical model in order to examine the instability of the system, emulsion water-xylene-tertbutyl oleyl glycosides [13]. In this system, tertbutyl oleyl glycosides (TBOG) surfactants are added to the emulsion of water-xylene as emulsifiers to enhance the stability of emulsion samples in terms of kinetic aspects. The new invention here is the use of TBOG surfactants, and they are made by reacting tert-butyl glycosides with oleic acid. This surfactant has more advantages compared to the type that has been previously studied by researchers, and this is attributable to its brighter colour obtained from its use of benzene solvents. By creating a mathematical model that can represent the process of flocculation and coalescence, the number of drops is then calculated for a certain period in the emulsion system. This data is afterwards used to determine the flocculation rate constant $(a)$ and coalescence rate constant $(K)$. Furthermore, the values of $\mathrm{a}$ and $\mathrm{K}$ can be used as data in designing emulsifier devices. Using the approach to the Van Den Tempel model to create a new mathematical model [14], here are 4 kinetics models with the $1^{\text {st }}, 2^{\text {nd }}$ and $3^{\text {rd }}$ have been studied by Borwankar [1]. The $4^{\text {th }}$ is a new model developed by the author, on the basis that generally the droplet flocculation process is faster than that of the coalescence, therefore the latter is the step that controls. No researcher has experimented using these four models for kinetic modeling involving the use of TBOG surfactants.

\subsection{Model Development for Flocculation and Coalescence Processes}

The droplet collecting mechanism of flocculation and coalescence in detail can be illus-

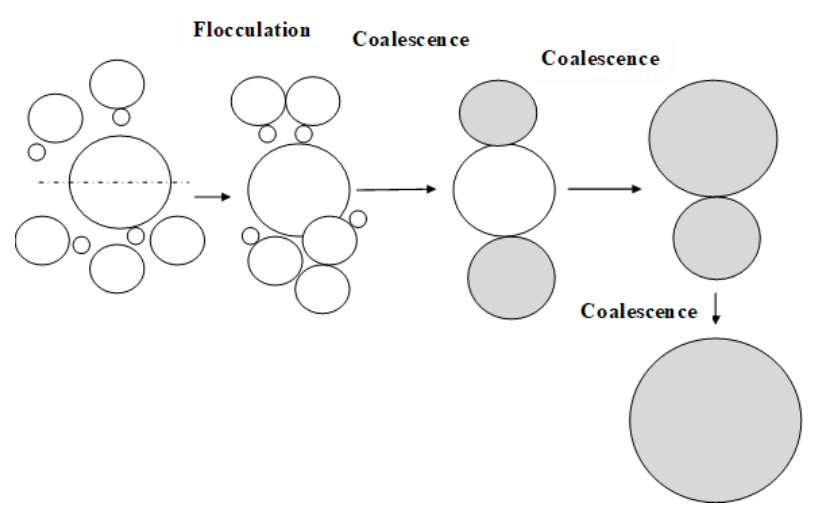

Figure 1. The droplet collecting mechanism is flocculation and coalescence trated as in Figure 1.

Flocculation is the composite of two or more droplets colliding to form aggregates as attached, while coalescence is when they collide to form a bigger drop (broke into one). In an emulsion, with the longer of the time, droplets of smaller size will tend to move towards and eventually attach to larger droplets, and this is called flocculation. Whereas, when small droplets break to form and attach to a large size droplet to form aggregates, the droplets will merge to form a larger one, and this step is called coalescence.

Flocculation had two effects on the emulsion stability: (i) an effective particle size increase, thus increasing the creaming rate and; (ii) increased coalescence possibilities since it is preceded by flocculation. For pericinetic flocculation, the speed of aggregate formation is strongly influenced by the diffusion of droplets past continuous phases [15-17]. The aggregation process is evidently governed by the mutual interaction forces between among the droplets. Under conditions where coalescence occurs much more rapidly than flocculation, the rate of the latter is equivalent to the quadrate of the particle concentration [1]. This rate in the absence of any energy barrier is given by Equation (1), which is known as the Smoluchowski equation $[18,19]$.

$$
\begin{gathered}
-\frac{d n}{d t}=4 \pi D R n^{2} \\
D=\frac{k T}{6 \pi \eta r}
\end{gathered}
$$

Where $D$ is the diffusion coefficient, $r$ is the radius of the droplet $(r=1 / 2 R), k$ is Boltzmann constant, $R$ is radius of collision, $\eta$ represents viscosity of the continuous phase, $T$ is temperature, $\mathrm{n}$ is number of droplets, and $t$ is time, from Equation (1) and (2) [20,21].

$$
-\frac{d n}{d t}=\frac{4 k T}{3 \eta} n^{2}=a n^{2}
$$

where $a=4 k T / 3 \eta=8 \pi D r$ is the flocculation rate constant. The $D$ is reciprocally connected with $r$, the product of $D r$ ha no correlation with the radius of the drop. It is certain that $a$ constantly persists constantly during the process, although the dimensions of the aggregate increases. By integrating Equation (3), the sum of drops (aggregate and major drops) at any time, is given by:

$$
\frac{1}{n_{t}}=\frac{1}{n_{o}}+a t
$$


or

$$
n_{t}=\frac{n_{o}}{1+a n_{o} t}
$$

Where $n_{o}$ is the number of initial drops; $n_{t}$ is the primary number of drops (from the initial set) fixed any time $t$. The sum of primary particles (not aggregated) $n$ set at any time $(t)$ is specified by the Equation (6).

$$
n=\frac{n_{o}}{\left(1+a n_{o} t\right)^{2}}
$$

The number of aggregates $\left(n_{v}\right)$ is obtained from Equations (5) and (6).

$$
n_{v}=\frac{a n_{o}^{2} t}{\left(1+a n_{o} t\right)^{2}}
$$

On orthokinetic flocculation, the rate constant is affected by the rapidity of agitation as an energy barrier. However, it is not detached of the drop radius [22-24]. The rate of flocculation with the presence of energy barrier is obtained using Equation (8).

$$
-\frac{d n}{d t}=4 \pi D r^{2} n \exp \left(-\frac{E}{k T}\right)
$$

From Equations (2) and (8),

$$
-\frac{d n}{d t}=\left(\frac{4 k T}{3 \eta}\right) \exp \left(-\frac{E}{k T}\right) n^{2}
$$

or

$$
-\frac{d n}{d t}=a^{\prime} n^{2}
$$

Where $a^{\prime}=(4 k T / 3 \eta) \exp (-E / k T)$ is flocculation rate constant with presence of energy barrier and $E$ is the activation energy. By integrating Equation (10), the number of total drops (aggregate and major drops) at any time is given by:

$$
\frac{1}{n_{t}}=\frac{1}{n_{o}}+a^{\prime} t
$$

Coalescence is the composite of two or more droplets colliding to form a bigger drop. Once flocculation occurs, the drops close to one another are parted by continuous thin-phase films. The films desiccate and break, which results in the coalescence of droplets due to the support forces for them, from both kinetic and gravitational forces. Contact mechanism and coalescence step was visualized [25]. The coalescence rate can be expressed in terms of a simple first order rate equation [1].

$$
-\frac{d n}{d t}=K n
$$

By integrating Equation (12), the number of total drops at any time is given by:

$$
n_{t}=n_{o} \exp (-K t)
$$

$K$ is coalescence rate constant. The above equation was the first proposed by Van den Tempel, it comes with the assumption that the aggregates consist of very large numbers of globules and that the coagulation is discontinued before any appreciable change in the size distribution of the drop occurs $[1,25]$.

1.2 Kinetic Modeling on Flocculation and Coalescence Process

Emulsion instability is a gradual process, which includes the formation of aggregates (flocculation), coalescence (film rupture) and phase separation [26]. $n$ is the number of primary (non aggregated) drops left at period $t ; m$ stands for the average number of drops in an aggregate; $\mathrm{n}_{f}$ represents the number of films in one aggregate. The illustration of flocculation and coalescence as regards the number of drops is given in Figure 2.

The shaded spheres indicate new drops, resulting from coalescence. As shown in Figure 1: $n_{o}=17 ; n=4 ; n_{v}=3 ; m=3.6 ; n_{t}=15$. Borwankar expressed that Van Den Tempel expand von Smoluchowski's theory by inserting coalescence kinetics. Assuming that the aggregate is linear, so that $n_{f}=m-1$. The lifetimes of thin films among drops is a major determinant of the coalescence rate. A reduction in $m$ was specified by the coalescence rate, which is considered to be proportionate to the films number $n_{f}=m-1$.

$$
\frac{d m}{d t}=a n_{o}-K(m-1)
$$

By integrating Equation (14), the average number of drops in one aggregate at any period $t$ is obtainable. The total amount of drops $n_{t}$ at any period $t$ is given by:

$$
n_{t}=n+n_{v} m
$$

Getting the final amount of droplets $n_{t}$ as a function of time $t$ made four mathematical models. 
Model 1: assumed that the drops aggregated linearly (linear).

From Equations (6), (7), (14), and (15), the total sum of drops $n_{t}$ as a function of period $t$ is given by Equation (16).

$n_{t}=\frac{n_{o}}{\left(1+a n_{o} t\right)}+\frac{a n_{o}^{2} t}{\left(1+a n_{o} t\right)^{2}}\left[\frac{a n_{o}}{K}+\left\{1-\frac{a n_{o}}{K}\right\} \exp (-K t)\right]$

$a n_{0} / K$ can be used to determine which of the two processes is in control of the overall step.

If $a n_{o} / K \gg>1$, this means coalescence is slower than flocculation, making it as the controlling step. On the other hand, when $a n_{o} / K<<1$, this means coalescence is much faster than flocculation, making flocculation as the controlling step. Furthermore, Equation (16) is a model equation which is used as a reference model and is designated as Model 1. This model is used as a comparison to the proposed models [27].

Model 2: Assumes that the droplet aggregates are non-linear (Two-dimensional)

In general, the films number in an aggregate $\left(n_{f}\right)$ can be written as:

$$
n_{f}=(2 m-3)
$$

The reduction in $m$ is due to the speed of coalescence, which is considered to be proportionate to the film number.

$$
\frac{d m}{d t}=a n_{o}-K(2 m-3)
$$

By integrating the Equation (18), one can obtain the average number of drops in an aggregate each period $t$ as:

$$
m=1.5+0.5 \frac{a n_{o}}{K}+0.5\left(1-\frac{a n_{o}}{K}\right) \exp (-2 K t)
$$

Equations (6), (7), (15), and (19) provide the sum of total drops $n_{t}$ expressed as a function of time:

$$
n_{t}=\frac{n_{o}}{\left(1+a n_{o} t\right)}+\frac{0.5 a n_{o}{ }^{2} t}{\left(1+a n_{o} t\right)^{2}}\left[1+\frac{a n_{o}}{K}+\left[1-\frac{a n_{o}}{K}\right] \exp (-2 K t)\right]
$$

Equation (20) represents the model equation of the Model 2. It indicates the relationship between the sum of total drops in an emulsion following any period, if flocculation and coalescence take place simultaneously.

Model 3: Assumes that the droplet is aggregated in a three-dimensional pattern (threedimensional)

In general, the number of films in an aggregate $\left(n_{f}\right)$ is presented by:

$$
n_{f}=3(m-2)
$$

The reduction in $m$ is due to the rapidity of coalescence, which is considered to be comparable to the film number.

$$
\frac{d m}{d t}=a n_{o}-K 3(m-2)
$$

By integrating the Equation (22), it is evident that the sum of average drops in one aggregate at any period $(t)$ is:

$$
m=2+\frac{a n_{o}}{3 K}+\left(1-\frac{a n_{o}}{3 K}\right) \exp (-3 K t)
$$

From Equations (6), (7), (15), and (23); it is clear that the sum of total drops $n_{t}$ expressed as a function of time:

$$
n_{t}=\frac{n_{o}}{\left(1+a n_{o} t\right)}+\frac{a n_{o}{ }^{2} t}{\left(1+a n_{o} t\right)^{2}}\left[1+\frac{a n_{o}}{3 K}+\left[1-\frac{a n_{o}}{3 K}\right] \exp (-3 K t)\right]
$$

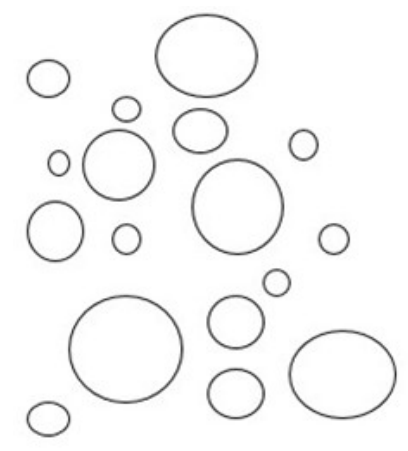

Initial condition

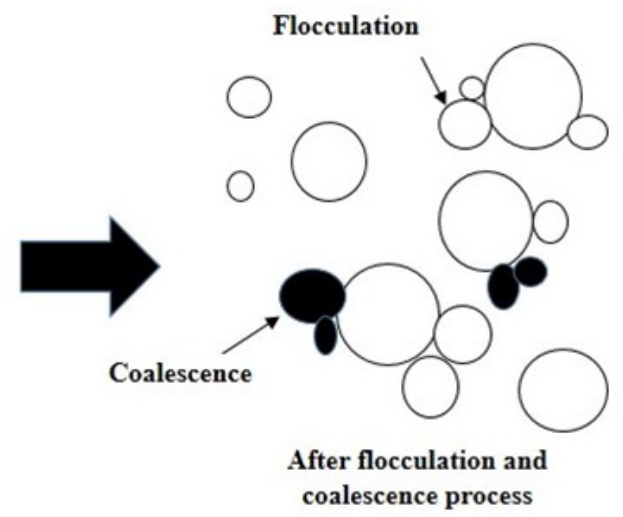

Figure 2. The combination of flocculation and coalescence that has occurred over time $t$ 
Equation (24) represents the model equation for the second proposed model (Model 3). This model points out the relationship between the total number of drops in an emulsion after any $t$ period, if flocculation and coalescence take place simultaneously [1].

\section{Model 4. Coalescence Control}

In this system, the drops are close to one another and the aggregates can be very big with a three dimensional shape. Every drop can be connected with two or more other drops. Therefore the number of contact points of the drops $m$ is no more equal to " $m-1$ ". With the mean film $p$ per drop, the number of films in every aggregate is as follows, $n_{f}=m p$

$$
\begin{aligned}
& -\frac{d n}{d t}=K p m \cdot n_{v} \\
& \frac{d m}{d t}=a n_{o}-K m p
\end{aligned}
$$

Using the same analysis as the one used previously, Van den Tempel gets the number of drops in strict dispersion such as the following:

$$
n_{t}=\frac{n_{o}}{\left(1+a n_{o} t\right)^{2}}\left(1+a n_{o} t\left[\frac{a n_{o}}{K p}+\left\{2-\frac{a n_{o}}{K p}\right\} \exp (-K p t)\right]\right)
$$

If the drops are considered to be of equal magnitude, the average number of films per drop, $p=12$, then:

$$
n_{t}=\frac{n_{o}}{\left(1+a n_{o} t\right)^{2}}\left(1+a n_{o} t\left[\frac{a n_{o}}{12 K}+\left\{2-\frac{a n_{o}}{12 K}\right\} \exp (-12 K t)\right]\right)
$$

This fourth model is one developed by authors theirself.

\section{Material and Methods}

\subsection{Materials}

The material used were terbutyl oleyl glycosides surfactant (its purity of $91.72 \%$ was measured by GCMS, produced from the reaction of tertbutyl glycosides with oleic acid), aquades, and xylene ( $99 \%$, Brataco).

\subsection{Methods}

The emulsion was generated by pouring 10 $\mathrm{mL}$ of aquades into a glass cup and then adding $10 \mathrm{~mL}$ of xylene and $5000 \mathrm{ppm}$ of surfactant tert-butyl olyl glycoside. This mixture was then stirred at different speeds (rpm: 1000, 2000, $5000,10000)$ for 3 minutes. The tool used was the Turrox model Homogenizer that had already been equipped with a rpm scale. After the emulsion was formed, two drops were taken and dripped on a preparation glass. The droplets were then observed using a camera equipped microscope which took photos every 10 minutes for 90 minutes. Afterwards, the photo was observed and the number of droplets was calculated at every $1 \mathrm{~cm}^{3}$, using software Image Raster 3.

\subsection{Analysis of Droplets}

The number of droplets was observed using a camera type Optilab Advanced Plus Model MTN016 and Binocular microscope Type XSZ170 , and the amount was subsequently calculated using the Software Image Raster 3.

\section{Results and Discussion}

The $1^{\text {st }}, 2^{\text {nd }}, 3^{\text {rd }}$, and $4^{\text {th }}$ models have two parameters, namely the flocculation rate constant $(a)$ and the coalescence rate constant $(K)$. They diverse until the error of the variance $\phi$ is minimized; where $\phi$ is illustrated as:

$$
\phi(a, K)=\sum_{i=1}^{n}\left(n_{c a l c, i}-n_{\text {exp }, i}\right)^{2}
$$

The obtained data for the number of drops at various times and stirring speeds with a surfactant concentration of 5000 ppm can be seen in Table1.

From Table 1, it can be observed that as the rotation speed got faster, the number of droplets increased, and their sizes became smaller. This is because a faster rotation of the stirring results in a stronger collision among molecules which eventually forms smaller drops. Subsequently, the xylene, water and surfactant TBOG mixture is stirred at varying speeds to form an emulsion. A surfactant is composed of hydrophilic and lipophilic groups in the molecule and has a tendency to be at the interface between two different phases of its polarity degree. It can form the film to produce an electric barrier at the interface of two different fluid phases. The formation of thick droplet films can be an insulator between the droplets, and this will reduce the surface tension of two different phase liquids, which means the droplets are not easily broken and the emulsion system becomes stable.

The emulsion system will become unstable, if left to stand for some time, and this is due to flocculation and coalescence. Table 1 shows the longer the time, the lesser the number of droplets. This is because they will experience flocculation and coalescence to form a larger droplet, and as a result, the number becomes less. The small ones experience flocculation process 
toward larger droplets, and then they attach to form an aggregate. Furthermore, small size droplets attached to those of larger size will melt, forming an even larger one. The larger the droplet size, the thinner the film between them, so the surface tension gets bigger and their tendency to collide gets stronger. Consequently, the droplets break out more easily to form larger ones, and this is called coalescence.

Also due to faster stirring, smaller coalescence rate constant $(K)$ and flocculation rate constant $(a)$ were obtained. Computed values of $(a)$ and $(K)$ can be seen in Table 2. From Table 2 for $1^{\text {st }}$ Model obtained, $a$ and $K$ are larger compared to other models. This is because here, flocculation rate surpasses that of coalescence. For a rotation speed at $1000 \mathrm{rpm}$ in $2^{\text {nd }}, 3^{\text {rd }}$, and $4^{\text {th }}$ Models, the flocculation process controls, and this results in a larger value of $K$, making $\left(a n_{o} / K\right)$ less than 1.

For a stirrer rotation speeds from $2000 \mathrm{rpm}$ to $10000 \mathrm{rpm}$, showed the same indication in these conditions that control the process of coalescence, this is because $a n_{0}$ value was greater than the value of $K$ and thus obtained $\left(a n_{0} / K\right)$ to be greater than 1 . It can be observed from Table 2 that the most visible step process is controlled by coalescence. Comparison of the effect of stirring speed on the value of $a$ and $K$ for the $4^{\text {th }}$ Model can be seen in Figure 3.

Figure 3 indicates that stirring speeds from 1000 to $10000 \mathrm{rpm}$ have the same trend, i.e. the faster the stirring, the smaller the obtained values of $a$ and $K$. This is because stronger collisions among molecules results in drops becoming more numerous and smaller in size, with that, $a$ and $K$ gets smaller, and as a result, the system has a more stable emulsion. At stirrer speeds 1000, 2000. and $5000 \mathrm{rpm}$, emulsion happens to be less stable, but it stabilized at $10000 \mathrm{rpm}$. A faster rotation speed stir- rer results in higher ranges of values obtained $\left(n t / n_{0}\right)$ at any given time. However, this is because the faster stirrer causes stronger collisions among molecules in order to obtain the dimensions and sum of the smaller drops more and more, giving the system a more stable emulsion. Hence, the impacts of this kinetic study were obtained at $10000 \mathrm{rpm}$ bringing about a more stable emulsion system. This data can be used in the design of emulsifier tools.

If inside the emulsion there is a surfactant, then the it will tend to move to fill the space between the water drop so it will reduce the surface tension of water drop $(\gamma)$, this results in a thicker water drop film and the force caused by a decrease in surface tension of the water drop will be smaller than the drainage force so that coalescence can be prevented and consequently a more stable emulsion system. If the emulsion solution is neglected over time, the surfactant performance will decrease, so flocculation and coalescence may occur. In this study it is found that most of the controlling results are the coalescence step. Flocculation and coalescence mechanism in detail can be illustrated in Figure 4.

Figure 4(a) depicts a surfactant molecule consisting of a head which is a hydrophylic group that likes water and a tail of the same group that likes oil. Figure 4(b) illustrates a water droplet surrounded by surfactant molecules in oil (xylene). Figure 4(c) shows water droplets that start to gather to form aggregates, and this is due to flocculation. Figure 4(d) illustrates water droplets that begin to break and form larger droplets, and this is due to coalescence.

If the time is longer, surfactant performance will decrease, causing the surface tension in the water drop to be greater than the drainage

Table 1. The relationship between the number of drops with time

\begin{tabular}{ccccc}
\hline $\begin{array}{c}t, \text { min- } \\
\text { utes }\end{array}$ & $\begin{array}{c}n\left(^{*} 10^{-6}\right), \mathrm{cm}^{-3} \\
\text { on } 1000 \mathrm{rpm}\end{array}$ & $\begin{array}{c}n\left(^{*} 10^{-6}\right), \mathrm{cm}^{-3} \\
\text { on } 2000 \mathrm{rpm}\end{array}$ & $\begin{array}{c}n\left(^{*} 10^{-6}\right), \mathrm{cm}^{-3} \\
\text { on } 5000 \mathrm{rpm}\end{array}$ & $\begin{array}{c}n\left(^{*} 10^{-6}\right), \mathrm{cm}^{-3} \\
\text { on } 10000 \mathrm{rpm}\end{array}$ \\
\hline 0 & 2.02 & 5.91 & 6.19 & 9.04 \\
10 & 1.58 & 4.68 & 5.19 & 8.34 \\
20 & 1.38 & 4.19 & 4.18 & 8.03 \\
30 & 1.23 & 3.49 & 3.95 & 7.89 \\
40 & 1.14 & 3.26 & 3.48 & 7.40 \\
50 & 1.05 & 3.04 & 3.22 & 6.79 \\
60 & 0.95 & 2.83 & 3.04 & 6.50 \\
70 & 0.78 & 2.44 & 2.83 & 6.33 \\
80 & 0.65 & 2.20 & 2.57 & 6.00 \\
90 & 0.51 & 1.92 & 2.48 & \\
\hline
\end{tabular}


force, and the film between water drops thinner, so they break easily and coalescence occurs. As a result, the number of droplets will decrease as they continue to increase in size. The droplet radius depends on the surface tension i.e. if the radius increases, the surface tension also increases, and consequently, droplets will easily break and melt into larger ones. Testing the proposed mathematical models of kinetic flocculation and coalescence can be done by comparing experimental data with data from the modelling.

When comparing results from the four models, there is not much of a difference. The

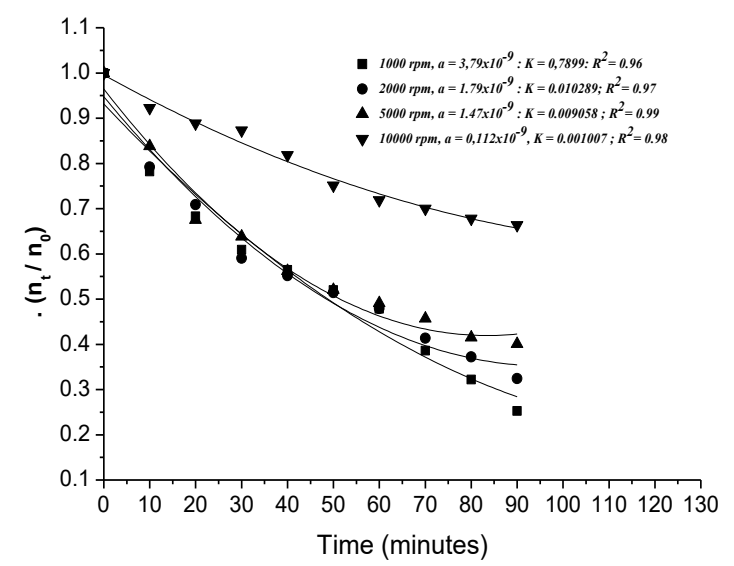

Figure 3. Effect of coalescence and flocculation rate constant on Model 4 $1^{\text {st }}$ Model has an average error of $2.66 \%$, the $2^{\text {nd }}$ with $4.16 \%, 3^{\text {rd }}$ with $3.15 \%$, and the $4^{\text {th }}$ with $2.22 \%$. From the information above, it is evident that the $1^{\text {st }}$ Model is the best to use. However, this is not in accordance with results of previous researches. Bowankar's most suitable model is the third model (three dimensional).

\section{Conclusions}

In the production of emulsions made from water, xylene and TBOG surfactants, it was discovered that the faster the speed of the stirrer rotation, the faster the collision between molecules will occur, and due to this fact, an emulsion will be formed with more and smaller droplets. As a result, the coalescence rate constant $(K)$ and the flocculation rate constant $(a)$ will be smaller, and finally, the emulsion will be more stable. From the four mathematical models used in calculating the value of the coalescence rate constant $(K)$ and the flocculation rate constant $(a)$ obtained, the value for the first model is greater than most of the other models, then the value $(K)$ of all models is obtained from $(K)$ those close to each other.

Effect of kinetic parameters (coalescence rate constants and flocculation rate constants) of the four proposed models, the $2^{\text {nd }}, 3^{\text {rd }}$ and $4^{\text {th }}$ models with stirrer rotation speeds of 1000

Table 2. The relationship between the kinetic parameters and step controlling for different systems

\begin{tabular}{|c|c|c|c|c|c|c|}
\hline Model & $\begin{array}{c}\text { Stiring } \\
\text { variation } \\
(\mathrm{rpm}) \\
\end{array}$ & $\begin{array}{c}(a) \\
\left(\mathrm{cm}^{3} \cdot \min ^{-1}\right)\end{array}$ & $\begin{array}{c}(K) \\
\left(\mathrm{min}^{-1}\right)\end{array}$ & $\begin{array}{c}n_{o} \\
\left(\mathrm{~cm}^{-3}\right) \times 10^{-6}\end{array}$ & $a n_{0} / K$ & $\begin{array}{c}\text { Controlling } \\
\text { Step }\end{array}$ \\
\hline Model 1. & 1000 & $9.98 \times 10^{-2}$ & $3.53^{*} 10^{-2}$ & 2.02 & $5.71^{*} 10^{6}$ & Coalescence \\
\hline \multirow[t]{3}{*}{ Linear } & 2000 & $1.50 \times 10^{-2}$ & $2.98^{*} 10^{-2}$ & 5.91 & $2.97^{*} 10^{6}$ & Coalescence \\
\hline & 5000 & $1.29 \times 10^{-2}$ & $2.99 * 10^{-2}$ & 6.19 & $2.67^{*} 10^{6}$ & Coalescence \\
\hline & 10000 & $1.13 \times 10^{-2}$ & $1.04 * 10^{-2}$ & 9.04 & $9.82^{*} 10^{6}$ & Coalescence \\
\hline Model 2. & 1000 & $1.47 \times 10^{-8}$ & $3.99^{*} 10^{-2}$ & 2.02 & 0.7442 & Flocculation \\
\hline Two- & 2000 & $1.19 \times 10^{-8}$ & $3.09 * 10^{-2}$ & 5.91 & 2.2760 & Coalescence \\
\hline \multirow[t]{2}{*}{ Dimensional } & 5000 & $1.01 \times 10^{-8}$ & $2.89^{*} 10^{-2}$ & 6.19 & 2.1633 & Coalescence \\
\hline & 10000 & $1.85 \times 10^{-9}$ & $1.36^{*} 10^{-2}$ & 9.04 & 1.2269 & Coalescence \\
\hline Model 3. & 1000 & $3.29 \times 10^{-8}$ & 0.3876 & 2.02 & 0.1714 & Flocculation \\
\hline Three- & 2000 & $2.12 \times 10^{-8}$ & 0.1241 & 5.91 & 1.0096 & Coalescence \\
\hline \multirow[t]{2}{*}{ Dimensional } & 5000 & $1.89 \times 10^{-8}$ & 0.1165 & 6.19 & 1.0042 & Coalescence \\
\hline & 10000 & $7.01 \times 10^{-9}$ & 0.0633 & 9.04 & 1.0011 & Coalescence \\
\hline Model 4. & 1000 & $3.79 \times 10^{-9}$ & 0.789900 & 2.02 & 0.00969 & Flocculation \\
\hline Coalescence & 2000 & $1.79 \times 10^{-9}$ & 0.010289 & 5.91 & 1.02817 & Coalescence \\
\hline \multirow[t]{2}{*}{ Control } & 5000 & $1.47 \times 10^{-9}$ & 0.009058 & 6.19 & 1.00456 & Coalescence \\
\hline & 10000 & $1.12 \times 10^{-10}$ & 0.001007 & 9.04 & 1.00544 & Coalescence \\
\hline
\end{tabular}

Concentration $\mathrm{TBOG}=5000 \mathrm{ppm}$ 

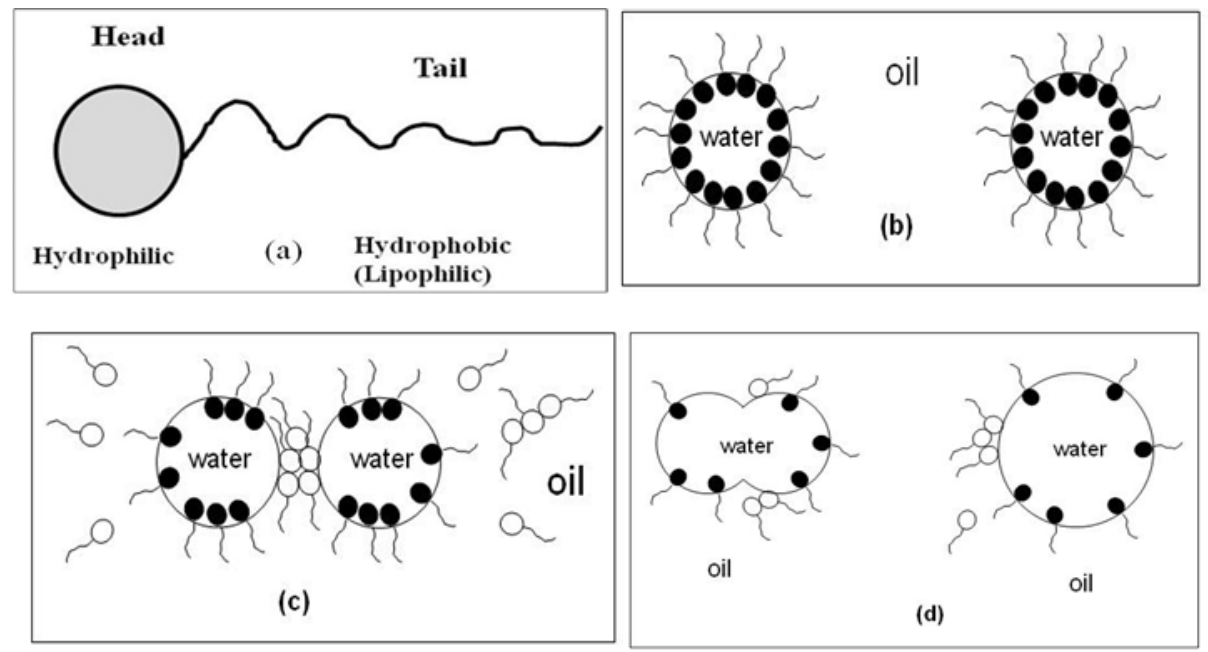

Figure 4. Flocculation and coalescence mechanism on emulsions using TBOG surfactants

rpm had the flocculation as the step of the controller. Furthermore, for other model, coalescence is a control step. However, of the four models at a stirrer speed of $10000 \mathrm{rpm}$, after the analysis of experimental data, the $4^{\text {th }}$ model is considered the most suitable because it has the smallest error of $2.22 \%$.

\section{Acknowledgement}

On this occasion, the authors would like to thank the Rector of University of Pembangunan Nasional "Veteran" Yogyakarta that has provided research fundings.

\section{References}

[1] Borwankar, R.P., Lobo, L.A., Wasan, D.T. (1992). Emulsion Stability-Kinetics of Flocculation and Coalescence. Colloids Surfaces, 69(2): 135-146.

[2] Dimitrova, T.D., Gurkov, N. Vassileva, Campbell, B., Borwankar, R.P. (2000). Kinetics of Cream Formation by the Mechanism of Consolidation in Flocculating Emulsions. Journal of Colloid and Interface Science, 230: 254267.

[3] Azizi, K., Nikazar, M. (2014). Kinetics Model of Destabilization of Oil Droplets in Oily Wastewater Emulsions. Journal of Dispersion Science and Technology, 35(11): 1581-1587.

[4] Anthony, J.O. (2000). Silicone Emulsions and Surfactants, Journal of Surfactants and Detergents, 3(3): 387-393.

[5] Berger, P.D., Hsu, C., Arendell, J.P. (1988). Designing and Selecting Demulsifiers for Optimum Field Performance on the Basis of Production Fluid Characteristics. Society or Petroleum Engineers, 3(4): 457-461.
[6] Chen, G., Tao, D. (2005). An Experimental Study of Stability of Oil-Water Emulsion. Fuel Processing Technology, 86(5): 499-508.

[7] Li, C., Mei, Z., Liu, Q., Wang, J., Xu, J., Sun, D. (2010). Formation and Properties of Paraffin Wax Submicron Emulsions Prepared by the Emulsion Inversion Point Method. Colloids Surfaces A: Physicochemical and Engineering Aspects, 356(1): 71-77.

[8] Raikar, N.B., Bhatia, S.R., Malone, M.F., McClements, D.J., Almedia-Rivera, C., Bongers, P., Henson, M.A. (2010). Prediction of Emulsion Drop Size Distributions with Population Balance Equation Models of Multiple Drop Breakage. Colloids Surfaces A: Physicochemical and Engineering Aspects, 361(1): 96-108.

[9] Danov, K.D., Ivanov, I.B., Gurkov, T.D., Borwankar, R.P. (1994). Kinetic Model for the Simultaneous Processes of Flocculation and Coalescence in Emulsion Systems. Journal of Colloid and Interface Science, 167(1): 8-17.

[10] Bernstein, D.F., Higuchi, W.I., Ho, N.F.H. (1971). Kinetics of Flocculation and/or Coalescence of Dilute Oil-in-Water Emulsions. Journal of Pharmaceutical Science, 60(5): 690-684.

[11] Menkiti, M.C., Nnaji, P.C., Nwoye, C.I., Onukwuli, O.D. (2010). Coag-Flocculation Kinetics and Functional Parameters Response of Mucuna Seed Coagulant to $\mathrm{pH}$ Variation in Organic Rich Coal Effluent Medium. Journal of Mineral and Material Characterization and Engineering, 9(2): 89-103.

[12] Yamaguchi, T., Nishizaki, K., Itai, S., Hayashi, H., Ohshima, H. (1995), Physicochemical Characterization of Parenteral Lipid Emulsion: Influence of Cosurfactants on Flocculation and Coalescence. Pharmaceutical Research, 12(9): 1273-1278. 
[13] Milkereit, G., Garamus, V.M., Veermans, K., Willumeit, R., Vill, V. (2005). Structures of Micelles Formed by Synthetic Alkyl Glycosides with Unsaturated Alkyl Chains. Journal of Colloid and Interface Science, 284(2): 704-713.

[14] Van den Tempel, M. (1958). Distance between Emulsified Oil Globules Upon Coalescence. Journal of Colloid Science, 13(2): 125-133.

[15] Thomas, D.N., Judd, S.J., Fawcett, N. (1999), Flocculation Modeling : A Review Water Resources. Water Resources, 33(7): 1579-1592.

[16] Bawab, A.A., Bozeya, A., Friberg, S. (2010). Geranyl Acetate Emulsions: Surfactant Association Structures and Stability. Journal of Dispersion Science and Technology, 31(5): 606-610.

[17] Ahmad, A.L., Chong, M.E., Bhatia, S. (2008). Population Balance Model (PBM) for Flocculation Process: Simulation and Experimental Studies of Palm Oil Mill Effluent (POME) Pretreatment. Chemical Engineering Journal, 140(1): 86-100.

[18] Coufort, C., Bouyer, D., Line, A., Haut, B. (2007). Modelling of Flocculation Using a Population Balance Equation. Chemical Engineering and Processing, 46(12): 1264-1273.

[19] Bourrel, M., Koukounis, Ch., Schechter, R., Wade, W. (1980). Phase and Interfacial Tension Behavior of Nonionic Surfactants. Journal of Dispersion Science and Technology, 1(1): 13-35.

[20] Thill, A., Moustier, S., Aziz, J., Wiesner, M.R., Bottero, J.Y. (2001), Floc Restructuring during Aggregation, Experimental Evidence and Numerical Simulation. Journal of Colloid and Interface Science, 243(1): 171-182.
[21] Xu, F., Wang, D., Riemer, N. (2008). Modeling of Flocculation Processes of Fine-Grained Particle using a Size Resolving Method. Continental Shelf Resources, 28(19): 2668-2677.

[22] Van den Ven, T.G.M., Mason, S.G. (1977). The Microrheology of Colloidal Dispersions. Colloid and Polymer Science, 255(8): 794-804.

[23] Honig, E.P., Rocbersen, G.J., Wiersema, P.H. (1971), Effect of Hydrodynamic Interaction on the Coagulation Rate of Hydrophobic Colloids. Journal of Colloid and Interface Science, 36(1): 79-109.

[24] Alam, M.M., Varadl, D., Aramaki, K. (2008). Solubilization of Triglycerides in Liquid Crystals of Nonionic Surfactant. Journal of Colloid and Interface Science, 325(1): 243-251.

[25] Clark, B.D., Morina, A.L., Martin, G.G., Wang, J.W., Spain, E.M. (2015). Au Nanoparticle Clusters from Deposition of a Coalescing Emulsion. Journal of Colloid and Interface Science, 450(15): 417-423.

[26] Ruiz-Rodriguez, P.E., Meshulam, D., Lesmes, U. (2014). Characterization of Pickering O/W Emulsions Stabilized by Silica Nanoparticles and Their Responsiveness to In vitro Digestion Conditions. Food Biophysics, 9(4): 406415.

[27] Marszall, L. (1981). The Effective HydrophileLipophile Balance op Nonionic Surfactant Mixtures. Journal of Dispersion Science and Technology, 2(4): 443-458. 